\title{
Patient-Ventilator Asynchrony in Critically-III Adult Patients Undergoing Invasive Mechanical Ventilation: Incidence, Risk Factors and Outcomes
}

\section{Yongfang Zhou}

Sichuan University West China Hospital

\section{Steven R Holets}

Mayo Clinic Rochester

Man Li

Mayo Clinic Rochester

Gustavo A Cortes Puentes

Mayo Clinic Rochester

\section{Todd J Meyer}

Mayo Clinic Rochester

Andrew C Hanson

Mayo Clinic Rochester

Phillip J Schulte

Mayo Clinic Rochester

Richard A Oeckler ( $D$ Oeckler.Richard@mayo.edu )

Mayo Clinic Rochester https://orcid.org/0000-0002-5796-5511

\section{Research}

Keywords: Patient ventilator interaction, Asynchrony, Dyssynchrony, Invasive mechanical ventilation, Double triggering, Flow starvation, Ineffective triggering, Cycle mismatch

Posted Date: December 17th, 2020

DOl: https://doi.org/10.21203/rs.3.rs-129357/v1

License: (c) (i) This work is licensed under a Creative Commons Attribution 4.0 International License. Read Full License 


\section{Abstract}

Background: Patient-ventilator asynchrony (PVA) is commonly encountered during mechanical ventilation of critically ill patients. Estimates of PVA incidence vary widely. Type, risk factors, and consequences of PVA remain unclear. We aimed to measure the incidence and identify types of PVA, characterize risk factors for development, and explore the relationship between PVA and outcome among critically ill, mechanically ventilated adult patients admitted to medical, surgical, and medical-surgical intensive care units in a large academic institution staffed with varying provider training background.

Methods: A single center, retrospective cohort study of all adult critically ill patients undergoing invasive mechanical ventilation for $\geq 12$ hours.

Results: A total of 676 patients who underwent 696 episodes of mechanical ventilation were included. Overall PVA occurred in 170 (24\%) episodes. Double triggering 92(13\%) was most common, followed by flow starvation $73(10 \%)$. A history of smoking, and pneumonia, sepsis, or ARDS were risk factors for overall PVA and double triggering (all $P<0.05$ ). Compared with volume targeted ventilation, pressure targeted ventilation decreased the occurrence of events (all $P<0.01$ ). During volume controlled synchronized intermittent mandatory ventilation and pressure targeted ventilation, ventilator settings were associated with the incidence of overall PVA. The number of overall PVA, as well as double triggering and flow starvation specifically, were associated with worse outcomes and fewer hospital-free days (all $P<0.01$ ).

Conclusion: Double triggering and flow starvation are the most common PVA among critically ill, mechanically ventilated patients. Overall incidence as well as double triggering and flow starvation PVA specifically, portend worse outcome.

\section{Introduction}

Invasive mechanical ventilation is essential for the treatment of critically ill patients with respiratory failure, yet a double-edged sword with potential to harm if ventilator settings do not meet patient demand. Suboptimal or mismatched ventilation selection may lead to patient ventilator asynchrony (PVA). PVA is common and may occur at any point during the course of mechanical ventilation. Its reported incidence varies widely, ranging from $10 \%-85 \%(1-5)$.

The factors that affect the occurrence of PVA can be related to the patient, the ventilator, or both. Patient factors include severity of illness, underlying diagnosis, indication for mechanical ventilation, and patient response to medical treatments $(3,6)$. Several studies $(3,7-10)$ have shown that patients with chronic obstructive pulmonary disease (COPD), in the presence of intrinsic PEEP, experience ineffective triggering or wasted efforts, delayed triggering, or prolonged cycling asynchronies. Another common PVA, double triggering, more frequently occurs in acute respiratory distress syndrome (ARDS) patients ventilated with low tidal volume (11). The choice of ventilator mode and settings may also play a role (3). 
PVA may result in adverse consequences including increased respiratory workload, patient discomfort, deterioration in gas exchange, diaphragmatic injury, and/or patient self-inflicted lung injury. PVA is associated with worse clinical outcomes objectively identified by increased duration of mechanical ventilation, length of intensive care unit (ICU) and hospital stay, and mortality (12-18). To date studies of PVA have mainly examined specific patient populations and/or ventilator modes and been limited by the timing and length of observations. The risk factors for, and clinical consequences of, PVA remain unclear. Though some may be benign, growing evidence suggests that certain PVAs may be more deleterious in the ventilatory management of patients with acute respiratory failure $(12,16,18,19)$.

Advanced methods of detecting PVA include esophageal pressure monitoring, diaphragm electrical activity, and software algorithms to continuously and automatically detect PVA. These techniques can provide robust information and help clinician detection of PVA but are quite complex to employ, requiring dedicated equipment and specialized expertise. As such these tools are not routinely used in clinical practice $(6,20,21-24)$. Furthermore, automated PVA detection has not been validated in large, heterogeneous populations and remains restricted mostly to research protocols $(6,21,24,25)$.

In contrast, ventilator waveforms require no additional equipment and are readily available for real-time, examination and interpretation by experienced clinicians (27). In current clinical practice, the most frequent and practical approach to detect PVA remains the evaluation of airway pressure, flow, and volume tracings on the ventilator display. Utilizing our local standardized mechanical ventilation practice and incorporating an established, routine PVA management by bedside respiratory therapists, we aimed to systematically investigate the prevalence of and identify risk factors for PVA, as well as define associations between PVA and clinical outcome in critically ill mechanically ventilated patients.

\section{Methods}

\section{Study Design and Patients}

This was a single-center, retrospective cohort study. From December 2018, through May 2019, adult patients admitted to the medical and surgical ICUs, Mayo Clinic, Rochester, MN, and requiring invasive mechanical ventilation for at least 12 hours, were included. Patients less than 18 years of age, with no evidence of spontaneous breathing, in a moribund state or palliative care were excluded. The study was reviewed and approved by the Mayo Clinic Institutional Review Board.

\section{Definition Of Pva And Counting Pva Events}

In October 2018, before study commencement, all Respiratory Therapists received PVA identification training consisting of analysis of the ventilator's pressure, flow, and volume waveforms. Following the training, RTs were required to pass a PVA identification competency exam with a minimum score of $85 \%$ detailed in Additional file S1. Our institution has a standardized mechanical ventilation guideline which includes respiratory therapists performing a 10-minute assessment of all mechanically ventilated 
spontaneously breathing patients to identify the occurrence of PVA. Assessments were conducted every 4 hours during routine ventilator checks or sooner if the RT felt an assessment was warranted. The presence and type of PVA were documented in the electronic medical record (EMR).

Definitions of various types of PVA were derived from descriptions in the literature as follows $(12,16,27-$ 30). Double-triggering: Sustained patient inspiratory effort beyond the ventilator inspiratory time resulting in the triggering and delivery of all or part of a second ventilator breath. Flow starvation: Ventilator inspiratory flow rate does not meet patients' inspiratory demand, represented by a concave deflection of the pressure-time tracing during the inspiratory phase. Ineffective triggering (wasted effort): Patient inspiratory effort prior to complete exhalation that does not trigger a breath. Represented by a temporary decrease in expiratory flow. Cycle mismatch included premature cycling and prolonged cycling. Premature cycling: Inspiratory effort continues beyond ventilator inspiratory time represented by a decrease in expiratory flow and airway pressure immediately after the onset of expiration; Prolonged cycling: Ventilator inspiratory time is longer than the patient's effort, represented as a sharp spike at the end of inspiration. Delayed Triggering: A delayed response by the ventilator to patient inspiratory effort. Represented by a marked decrease in pressure before the ventilator delivering a breath. Overall PVA included any type of PVA listed as above.

\section{Data Collection}

Demographics, mechanical ventilation data, and clinical outcomes were extracted from EMR, listed as the following: (1) Demographics, chronic comorbidities; (2) Reasons for initial mechanical ventilation; (3) PVA assessment: the prevalence of any type of PVA; (4) Ventilator mode and ventilator settings at the time of PVA assessment, and the classification of ventilator modes listed in Additional file S2; (5) Clinical outcomes: mechanical ventilation duration, ventilator-free days at day 28 , length of ICU and hospital stay, ICU and hospital mortality. Ventilator free days at day 28 were defined as the number of ventilator-free days and alive through 28 days after mechanical ventilation initiation(31). All data were collected during the first episode of mechanical ventilation during the first ICU stay, whether or not multiple episodes occurred during the same hospital stay.

\section{Statistical Analysis}

Incidence of PVA (overall, and by type) is described using the observed percentage of subjects with the event and using cumulative incidence curves, estimated where death and weaning from ventilator are competing risks. Assessments of the association of PVA with baseline patient characteristics and ventilator settings using a recurrent events analysis Prentice, Williams, and Peterson gap time (PWP-GT) model (32), and the correlation of PVA event with hospital mortality and hospital-free days using adjusted logistic regression and multivariable-adjusted linear regression respectively are described in Additional file S3. 


\section{Results}

\section{Baseline patient characteristics and incidence of PVA throughout the course of mechanical ventilation}

A total of 676 patients who underwent 696 episodes of mechanical ventilation were included. Thirteen patients had more than one episode of hospital stay (Figure S1). Demographics, comorbidities, reasons for initial mechanical ventilation, and initial ventilator mode are shown in Table 1. During the entire course of 696 episodes of mechanical ventilation, overall PVA occurred in 170(24\%) episodes(Figure S1). The most common PVA was double triggering $92(13 \%)$ episodes, followed by flow starvation $73(10 \%)$ episodes. The incidence of cycle mismatch 29(4\%) was similar to ineffective effort 27(4\%). Delayed triggering rarely occurred;7(1\%) episodes (Table 1$)$. Double triggering $(2.11 \%$ vs. $1.09 \%)$ and flow starvation ( $1.63 \%$ vs. $0.76 \%$ ) occurred more frequently in volume targeted ventilation (VC) than in pressure targeted ventilation (PC) (both $P<0.01$ ) table S1.

The cumulative incidences of patients experiencing all types of PVA at day 12 in table S2, were similar to those during the whole period of mechanical ventilation in table 1. Figure 1 presents the cumulative incidence of PVA over the first 12 days of mechanical ventilation. The first 5 days were associated with a higher rate of cumulative incidence for double triggering, and the first 8 days with a higher rate for flow starvation. Incidences of cycle mismatch and ineffective effort increased gradually through the first 12 days. Occurrence of delayed triggering started after the third day.

\section{Association of PVA with baseline patient characteristics and ventilator settings}

PWP-GT model was used to analyze the association of time to PVA event with patient characteristics (Table 2) and ventilator settings (Table 3). History of smoking ( $H R=1.46,95 \% C L, 1.13-1.89 ; P=0.004)$, cirrhosis ( $\mathrm{HR}=1.57,95 \% \mathrm{CL}, 1.06-2.32 ; P=0.024)$, and of reasons for initial mechanical ventilation, pneumonia/sepsis/ARDS ( $H R=1.48,95 \% \mathrm{CL}, 1.01-2.16)$ and other $(\mathrm{HR}=1.52,95 \% \mathrm{CL}, 1.02-2.27)$ compared to post-surgery $(P=0.007)$ were risk factors for overall PVA. However, heart disease $(H R=0.65$, $95 \% \mathrm{CL}, 0.50-0.85 ; P=0.002)$ was negatively associated with overall PVA. When analysis for the specific type of PVA, history of smoking, kidney disease, and pneumonia/sepsis /ARDS in comparison with postsurgery were risk factors for double triggering, while heart disease and immunosuppression were associated with decreased risk of this event; cirrhosis and ideal body weight (per $10 \mathrm{~kg}$ ) were associated with increased risk of flow starvation.

Adjusting for baseline characteristics, chronic comorbidities, and reasons for initiation of mechanical ventilation, in patients on synchronized intermittent mandatory ventilation with volume-controlled ventilation (VC-SIMV), increasing peak inspiratory flow setting (HR=1.12, 95\% CL, 1.04-1.20; $P=0.002$ ) was associated with increased risk of overall PVA, while increasing PEEP ( $\mathrm{HR}=0.82,95 \% \mathrm{CL}, 0.70-0.95$; $P=0.009$ ) was associated with decreased risk of PVA event. In PC ventilation, an inspiratory pressure above PEEP of $12 \mathrm{cmH}_{2} \mathrm{O}$, was associated with increased risk of PVA event (HR: 1.10 per $\mathrm{cmH}_{2} \mathrm{O}, 95 \% \mathrm{Cl}$ : 1.03-1.17, $P=0.006)$. However, in VC ventilation, no association was observed between ventilator settings and overall PVA event. 


\section{Patient Outcome: Correlation of PVA with hospital mortality and hospital-free days}

Patients with overall PVA, double triggering, and flow starvation were associated with fewer ventilator-free days, longer duration of mechanical ventilation, longer ICU and hospital stay, and higher ICU and hospital mortality than those without (all $P<0.01$ ) in table S3.

In the analysis of the effect of PVA on subsequent outcome (length of hospital stay and hospital mortality post-invasive ventilation), 97 patients who died on ventilator were excluded and a total of 599 patients were analyzed. $128(21.4 \%)$ patients experienced at least one PVA event, hospital-free days at day 28 were $15.2(0.1-21.2)$ vs. $19.7(11.8-23.5)$ days, hospital mortality $14 \%$ vs. $7 \%$ in patients with and without PVA respectively (Table 4). After adjustment for history of smoking, heart disease, reasons for mechanical ventilation and initial ventilation modes, overall PVA (RR=-4.00; 95\% CL, -5.81 to -2.18 ; $P<0.001)$, double triggering ( $R R=-3.12 ; 95 \% \mathrm{CL},-5.43$ to $-0.81 ; P=0.008)$ and flow mismatch $(\mathrm{RR}=-4.24$; $95 \% \mathrm{CL},-7.01$ to $-1.47 ; P=0.003$ ) were each associated with fewer hospital-free days, but no association was observed between PVA and hospital mortality $(P>0.05)$ in table 5 .

\section{Discussion}

The current study examines the incidence and consequences of PVA in medical, surgical, and medicalsurgical patients managed across a number of general and subspecialty ICUs staffed by providers of varying background (internal medicine/Pulm CC, anesthesia, surgery). The main findings include: (1) Overall, PVA was common. Double triggering was most prevalent, followed by flow starvation; (2) Risk factors for the development of PVA - and double triggering specifically - include a history of smoking, sepsis, pneumonia, or ARDS as etiology of respiratory failure. PC ventilation was associated with a lower overall incidence of PVA, double triggering, and flow starvation compared to VC; (3) Double triggering, flow starvation, and the total number of PVA per patient were associated with worse outcome and fewer hospital-free days.

In our study, the overall prevalence of PVA in adult, critically ill patients over their entire course of mechanical ventilation was $24 \%$. The most prevalent PVA was double triggering, followed by flow starvation. This finding is, to some extent, consistent with previous studies reporting that double triggering occurs in most mechanically ventilated patients $(11,13,15,33)$. However, others have shown that the incidence of PVA varies widely with the most common being ineffective effort $(1,2,4,5,7)$. This may be explained by differences in study population (e.g., COPD, trauma, medical or surgical patients), observation time (e.g., 1-10min, 30 min, or one day), detection method (e.g., clinical assessment, waveform continuously monitored, detection of esophageal pressure and electrical activity of the diaphragm), and ventilator settings $(1,2,4,5,7)$.

PVA can occur throughout the course of mechanical ventilation and varies widely over time $(15,33)$. In a recent proof of concept study, Marchuk et al (34) developed a Hidden Markov model to predict the time 
course of PVA and inferred the probability that the number of PVA events would be above a given threshold, based on discrete time-series data in 51 mechanically ventilated patients. Here we report the cumulative incidence of PVA, identifying the first 12 days after mechanical ventilation initiation as a critical period over which the risk for development of any PVA event increases. The first 5 days appear to be a critical time with a high likelihood of developing double triggering; Over the first 8 days, flow starvation. This finding may suggest that critically ill, mechanically ventilated patients could benefit from closer monitoring of those with a higher risk of PVA over this time period, to enable early identification and intervention upon PVA to improve patient-ventilator interaction.

\section{Factors associated with overall PVA}

Patient factors may predict PVA. A history of smoking, cirrhosis, and pneumonia/sepsis/ARDS as etiology of respiratory failure, as opposed to a post-surgery status, were positively associated with overall PVA events. Conversely, heart disease was negatively associated with overall PVA. Several studies reported that COPD, ARDS, and greater severity of illness favor the occurrence of PVA $(3,11,33)$. In PC ventilation, higher inspiratory pressure ( $>12 \mathrm{cmH}_{2} 0$ above PEEP), and in VC-SIMV mode, higher inspiratory flow were associated with a higher risk of PVA, while higher PEEP levels were associated with lower risk. During VC ventilation, no association was observed between ventilator settings and overall PVA event. Robinson et al (24) found ventilator asynchrony was more common in SIMV with set breathing frequencies of $>10$ breaths/min in trauma patients. Similar to the previous studies $(30,35,36)$, the use of $P C$ ventilation was associated with better patient-ventilator interaction than VC ventilation, but requires careful monitoring to avoid delivery of larger than targeted volumes.

\section{Factors associated with double triggering and flow starvation}

Double triggering occurs when there is a mismatch between set tidal volume or inspiratory time and patient's ventilatory demand $(16,29,3137)$. Risk factors include a history of smoking, chronic kidney disease, and pneumonia/sepsis/ARDS, while chronic heart disease and immunosuppression had a reduced risk of double triggering. We speculate that kidney disease may cause acidosis, resulting in increased central respiratory drive. Pulmonary function impairment might be more severe in patients with pneumonia/sepsis/ARDS than those patients intubated in the postoperative period, and this may lead to high ventilatory demand.

Flow starvation occurs when ventilator flow rate is less than patient demand. Our results demonstrate a positive correlation between cirrhosis and ideal body weight with flow starvation. We speculate that patients with greater ideal body weight may need higher flow and that cirrhosis might cause increased ventilatory demand or neural drive through liver-lung cross talk.

We confirm previous reports $(12,30,35,36)$ that $\mathrm{VC}$ ventilation is associated with more frequent double triggering and flow mismatch events, perhaps due to inadequate tidal volume or flow as a result of strict limitation by operators. However, de Haro et al found a higher percentage of double cycling occurred in PCV than in VCV with constant flow or decelerated flow (33). A plausible explanation for this discrepancy 
could be related to differences in study population and ventilator settings. We did not analyze the influence of the ventilator mode-specific settings on the occurrence of double triggering and flow mismatch due to the limited number of events.

\section{Outcome}

In accordance with previous studies $(12,15,17,38)$, patients in our cohort who developed PVA had worse outcomes. Patients with greater overall PVA were associated with fewer ventilator-free days (longer duration of mechanical ventilation), longer ICU and hospital stay, and higher ICU and hospital mortality than those without. Overall PVA independently predicted shorter hospital-free days at day 28. After adjusting for a history of smoking, heart disease, reasons for mechanical ventilation, and initial ventilation mode, no association was observed between overall PVA and hospital mortality at day 28.

However, examining PVA in trauma patients (24) or in the early phase of weaning (38), with a short observation showed that asynchrony index (number of PVA events/total respiratory rate $\times 100$ ) $>10 \%$ was not associated with adverse clinical outcome. Additionally, Colomb et al(18) found that only clusters of ineffective triggering were correlated with a worse outcome. These discrepancies may be attributed to differences in patient population, the timing and duration of observation, and/or the definition of asynchrony employed.

Our study examined the relationships of double triggering, flow starvation, and patient outcome. Both were associated with worse outcomes. As expected, the total delivered volume during double triggering events was much larger than the set/targeted tidal volume, often double or more a normal breath $(30,33)$, which could lead to overinflation. Stronger spontaneous inspiratory effort during flow starvation can cause harmful transpulmonary pressure swings, which might lead to occult pendelluft and consequent regional lung overdistension $(39,40)$. Those mechanisms might cause ventilator induced lung injury and worsen outcomes (40). Our study reinforced the association of PVA with a poorer prognosis, but whether the relationship between PVA and outcome is causative or associative requires further investigation.

\section{Strength}

To our knowledge, this is the first and largest study to systemically investigate the incidence of overall and specific types of PVA, their risks, and associated outcomes among a heterogeneous population of ICU patients in a large, academic institution, where well trained RTs routinely manage PVA per local standardized clinical practice guidelines. This study used a PWP-GT approach to estimate the correlation of time to PVA events with factors related to patient characteristics, ventilator settings - time-dependent covariates throughout the entire course of mechanical ventilation; and analyzed the prediction of time to PVA events on the subsequent outcomes after extubation or weaning success.

\section{Limitation}


Our study has several limitations. First, this is a single-center, retrospective cohort study, which may limit generalizability.Second, PVA detection relied on ventilator waveform analysis by RT's at designated timepoints, thus the incidence of PVA is likely underestimated. Though software that provides continuous monitoring and automatic detection of PVA may be available in the near future, it is not currently part of routine clinical practice.This study analyzed a real-world method for identifying PVA applicable to any bedside intensive care practice. Lastly, for reasons of statistical power, factors associated with double triggering and flow starvation related to ventilator settings were not analyzed.

\section{Conclusion}

PVA are common, with double triggering and flow starvation encountered most often among critically-ill patients undergoing at least 12 hours of invasive mechanical ventilation. Occurrence is associated with worse outcome, including fewer hospital free days. Patient characteristics including day of mechanical ventilation and etiology of respiratory failure may predict development of PVA and help to identify at-risk individuals for closer monitoring and early intervention. Further investigations are needed to determine whether the relationship between PVA and outcome is associative or causal.

\section{Abbreviations}

PVA: patient-ventilator asynchrony; PEEP: positive end of expiratory pressure; ARDS: acute respiratory distress syndrome; COPD: chronic obstructive pulmonary disease; PWP-GT: Prentice, Williams, and Peterson gap time; EMR: electronic Medical record; VC: volume targeted ventilation; PC: pressure targeted ventilation; VC-SIMV: synchronized intermittent mandatory ventilation with volume-controlled ventilation; PC-SIMV: synchronized intermittent mandatory ventilation with pressure controlled ventilation.

\section{Declarations}

\section{Acknowledgments}

We appreciate the respiratory therapists of Mayo Clinic for their dedication to patient care and their support of this study. Lei Fan, IT Analyst/Programmer in Department of Information Technology, and Grant D Wilson for their help with this study.

\section{Authors' Contributions}

YFZ, RAO and SRH conceived and designed the protocol, YFZ, SRH, ML, TJM and RAO were involved in acquisition of funding and data. ACH and PJS organized and performed the analysis of the data, and wrote the statistical methodology. All authors participated in the interpretation of the data. YFZ drafted the manuscript, and GACP, SRH, RAO participated in the critical revision of the manuscript. All authors approved the final version of the manuscript.

\section{Funding}


This trial was funded by Critical Care Research Committee in Mayo Clinic, Rochester, Minnesota, US.

\section{Availability of data and materials}

The datasets used and/or analyzed during the current study are available from the corresponding author on reasonable request.

\section{Ethics declarations}

\section{Ethics approval and consent to participate}

This study was approved by the Mayo Clinic Institutional Review Board, under the approval number \#180098365, June $27^{\text {th }}, 2019$.

\section{Competing interests}

All authors have no competing interests.

\section{Consent for publication}

Not applicable.

\section{References}

1. Chao DC, Scheinhorn DJ, Stearn-Hassenpfl ug M. Patient-ventilator trigger asynchrony in prolonged mechanical ventilation. Chest. 1997;112(6):1592-9.

2. Thille AW, Rodriguez P, Cabello B, Lellouche F, Brochard L. Patient ventilator asynchrony during assisted mechanical ventilation. Intensive Care Med. 2006;32(10):1515-22.

3. Holanda MA, Vasconcelos RDS, Ferreira JC, Pinheiro BV. Patient-ventilator asynchrony. J Bras Pneumol. 2018 Jul-Aug; 44(4):321-333.

4. de Wit M, Pedram S, Best AM, Epstein SK. Observational study of patient-ventilator asynchrony and relationship to sedation level. J Crit Care. 2009;24(1):74-80.

5. Colombo D, Cammarota G, Alemani M, Carenzo L, Barra FL, Vaschetto R, et al. Efficacy of ventilator waveforms observation in detecting patient-ventilator asynchrony. Crit Care Med. 2011;39(11):24527.

6. de Haro C, Ochagavia A, López-Aguilar J, Fernandez-Gonzalo S, Navarra-Ventura G, Magrans R, Montanyà J, Blanch L. Asynchronies in the Intensive Care Unit (ASYNICU) Group. Patient-ventilator asynchronies during mechanical ventilation: current knowledge and research priorities.

7. Alexopoulou C, Kondili E, Plataki M, Georgopoulos D. Patient-ventilator synchrony and sleep quality with proportional assist and pressure support ventilation. Intensive Care Med. 2013 Jun;39(6):10407.

8. Branson RD. Patient-ventilator interaction: the last 40 years. Respir Care. 2011;56(1):15-24. 
9. Nava S, Bruschi C, Fracchia C, Braschi A, Rubini F. Patient-ventilator interaction and inspiratory effort during pressure support ventilation in patients with different pathologies. Eur Respir J. 1997;10(1):17783.

10. Vasconcelos RS, Sales RP, Melo LHP, Marinho LS, Bastos VP, Nogueira ADN, Ferreira JC, Holanda MA. Influences of Duration of Inspiratory Effort, Respiratory Mechanics, and Ventilator Type on Asynchrony with Pressure Support and Proportional Assist Ventilation. Respir Care. 2017 May;62(5):550-7.

11. Pohlman MC, McCallister KE, Schweickert WD, Pohlman AS, Nigos CP, Krishnan JA, et al. Excessive tidal volume from breath stacking during lung-protective ventilation for acute lung injury. Crit Care Med. 2008;36(11):3019-23.

12. Thille aW, rodriguez $P$, cabello B, lellouche F. Brochard I. Patient-ventilator asynchrony during assisted mechanical ventilation. Intensive care Med. 2006;32:1515-22.

13. Beitler JR, Sands SA, Loring SH, Owens RL, Malhotra A, Spragg RG, et al. Quantifying unintended exposure to high tidal volumes from breath stacking dyssynchrony in ARDS: the BREATHE criteria. Intensive Care Med. 2016;42(9):1427-36.

14. Yonis H, Gobert F, Tapponnier R, Guérin C. Reverse triggering in a patient with ARDS. Intensive Care Med. 2015;41(9):1711-2.

15. Blanch L, Villagra A, Sales B, Montanya J, Lucangelo U, Luján M, et al. Asynchronies during mechanical ventilation are associated with mortality. Intensive Care Med. 2015;41(4):633-41.

16. Gilstrap D, Maclntyre N. Patient-ventilator interactions. Implications for clinical management. Am J Respir Crit Care Med. 2013;188(9):1058-68.

17. de Wit M, Miller KB. green Da, ostman He, gennings c, epstein sK. Ineffective triggering predicts increased duration of mechanical ventilation. Crit Care Med. 2009;37:2740-5.

18. Vaporidi K, Babalis D, chytas a, lilitsis e, Kondili e, amargianitakis v, et al. Clusters of ineffective efforts during mechanical ventilation: impact on outcome. Intensive care Med 2017; 43: $184-91$.

19. Colombo D, cammarota g, Bergamaschi v, De lucia M, corte navalesi FD P. Physiologic Response to Varying Levels of Pressure Support and Neurally Adjusted Ventilatory Assist in Patients With Acute Respiratory Failure. Intensive Care Med. 2008 Nov; 34(11):2010-8.

20. Murias g. villagra a, Blanch I. Patient-ventilator dyssynchrony during assisted invasive mechanical ventilation. Minerva Anestesiol. 2013;79:434-44.

21. Dres M, Rittayamai N, Brochard L. Monitoring patient-ventilator asynchrony. Curr Opin Crit Care. 2016 Jun;22(3):246-53.

22. Branson RD, Blakeman TC, Robinson BR. Asynchrony and dyspnea. Respir Care. 2013 Jun;58(6):973-89.

23. Gentile MA. Cycling of the mechanical ventilator breath. Respir Care. 2011;56(1):52-60.

24. Robinson BR, Blakeman TC, Toth $P$, Hanseman DJ, Mueller E, Branson RD. Patient-ventilator asynchrony in a traumatically injured population. Respir Care. 2013 Nov;58(11):1847-55. 
25. Subirà C, de Haro C, Magrans R, Fernández R, Blanch L. Minimizing Asynchronies in Mechanical Ventilation: Current and Future Trends. Respir Care. 2018 Apr;63(4):464-78.

26. Ramirez II, Arellano DH, Adasme RS, Landeros JM, Salinas FA, Vargas AG, Vasquez FJ, Lobos IA, Oyarzun ML, Restrepo RD. Ability of ICU Health-Care Professionals to Identify Patient-Ventilator Asynchrony Using Waveform Analysis. Respir Care. 2017 Feb;62(2):144-9.

27. Pham T, Telias I, Piraino T, Yoshida T, Brochard LJ. Asynchrony Consequences and Management. Crit Care Clin. 2018 Jul;34(3):325-41.

28. Chacón E, Estruga A, Murias G, Sales B, Montanya J, Lucangelo U, Garcia-Esquirol O, Villagrá A, Villar J, Kacmarek RM, Burgueño MJ, Blanch L, Jam R. Nurses' detection of ineffective inspiratory efforts during mechanical ventilation. Am J Crit Care. 2012 Jul;21(4):e89-93.

29. Figueroa-Casas JB, Montoya R. Effect of Tidal Volume Size and Its Delivery Mode on PatientVentilator Dyssynchrony. Ann Am Thorac Soc. 2016 Dec; 13(12):2207-2214.

30. Georgopoulos D, Prinianakis G, Kondili E. Bedside waveforms interpretation as a tool to identify patient-ventilator asynchronies. Intensive Care Med. 2006;32:34-47.

31. Writing Group for the PReVENT Investigators; Fabienne D, Simonis AS, Neto JM, Binnekade A, Braber, Karina CM, Bruin RM, Determann G-J, Goekoop J, Heidt J, Horn G, Innemee, Evert de Jonge, Nicole P, Juffermans, Peter E, Spronk, Lotte M, Steuten P, Tuinman R, Rob BP, de Wilde, Marijn Vriends, Marcelo Gama de Abreu, Paolo Pelosi, Marcus J Schultz. Effect of a Low vs Intermediate Tidal Volume Strategy on Ventilator-Free Days in Intensive Care Unit Patients Without ARDS: A Randomized Clinical Trial. JAMA. 2018; 320(18):1872-1880.

32. Amorim LDAF, Cai J. Modelling recurrent events: a tutorial for analysis in epidemiology. Int J Epidemiol. 2015;44(1):324-33.

33. de Haro C, López-Aguilar J, Magrans R, Montanya J, Fernández-Gonzalo S, Turon M, Gomà G, Chacón E, Albaiceta GM, Fernández R, Subirà C, Lucangelo U, Murias G, Rué M, Kacmarek RM, Blanch L. Asynchronies in the Intensive Care Unit (ASYNICU) Group. Double Cycling During Mechanical Ventilation: Frequency, Mechanisms, and Physiologic Implications. Crit Care Med. 2018 Sep;46(9):1385-92.

34. Marchuk Y, Magrans R, Sales B, Montanya J, López-Aguilar J, de Haro C, Gomà G, Subirà C, Fernández R, Kacmarek RM, Blanch L. Predicting Patient-ventilator Asynchronies with Hidden Markov Models. Sci Rep. 2018 Dec 4; 8(1):17614.

35. Yang LY, Huang YC, Macintyre NR. Patient-ventilator synchrony during pressure-targeted versus flowtargeted small tidal volume assisted ventilation. J Crit Care. 2007;22(3):252-7.

36. Maclntyre NR, McConnell R, Cheng KC, Sane A. Patient-ventilator flow dyssynchrony: flow-limited versus pressure-limited breaths. Crit Care Med. 1997 Oct;25(10):1671-7.

37. Kallet RH, Campbell AR, Dicker RA, Katz JA, Mackersie RC. Effects of tidal volume on work of breathing during lung-protective ventilation in patients with acute lung injury and acute respiratory distress syndrome. Crit Care Med. 2006 Jan;34(1):8-14. 
38. Rolland-Debord c, Bureau c, Poitou t, Belin I, clavel M, Perbet s, et al. Prevalence and prognosis impact of patient-ventilator asynchrony in early phase of weaning according to two detection methods. Anesthesiology 2017; 127:989-97.

39. Yoshida T, Roldan R, Beraldo MA, et al. Spontaneous effort during mechanical ventilation: Maximal injury with less positive end-expiratory pressure. Crit Care Med 2016; 44:e678-e688.Yoshida T, Fujino $\mathrm{Y}$, Amato MB, et al. Fifty years of research in ARDS. Spontaneous breathing during mechanical ventilation. Risks, mechanisms, and management. Am J Respir Crit Care Med 2017; 195:985-992.

40. Yoshida T, Fujino Y, Amato MB, et al. Fifty years of research in ARDS. Spontaneous breathing during mechanical ventilation. Risks, mechanisms, and management. Am J Respir Crit Care Med. 2017;195:985-92.

\section{Tables}


Table 1. Patient demographics, comorbidities, initial ventilator mode, and number and percentage of all patients experiencing events at any time during mechanical ventilation*

Overall $(N=696)$

Age (y) $64(52,72)$

Sex

Male

$403(58 \%)$

Female

$293(42 \%)$

Ideal body weight $(\mathrm{kg} ; \mathrm{n}=695)$

$64.2(54.3,73.3)$

Apache III score $(n=695)$

$95(62,122)$

Chronic comorbidities

History of smoking

Heart disease

Lung disease

395 (57\%)

Kidney disease

$292(42 \%)$

Immunosuppression

Neurologic

$182(26 \%)$

Cirrhosis

$161(23 \%)$

$152(22 \%)$

$96(14 \%)$

$45(6 \%)$

Reason for ventilation $(n=685)$

Post-surgery

$241(35 \%)$

Pneumonia/Sepsis/ARDS

$201(29 \%)$

Neuro

$84(12 \%)$

Other

$159(23 \%)$

Initial ventilator mode†

VC

$426(61 \%)$

VC-SIMV

$140(20 \%)$

PC/PC-SIMV

$130(19 \%)$

Patient ventilator asynchrony (PVA) events

Overall PVA \#

$170(24 \%)$

Double trigger

$92(13 \%)$ 
Table 1. Patient demographics, comorbidities, initial ventilator mode, and number and percentage of all patients experiencing events at any time during mechanical ventilation*

Overall $(N=696)$

Flow mismatch

$73(10 \%)$

Cycle mismatch

$29(4 \%)$

Ineffective effort

27 (4\%)

Trigger delay

$7(1 \%)$

* Variables are summarized as median (25th percentile, 75th percentile) or number and percentage as appropriate. When all data are not available, numbers with complete data are presented. Data represent 696 episodes of mechanical ventilation in 676 unique patients. In total, 13 patients had greater than 1 episode, with 1 patient having 6 episodes.

† Initial ventilator mode reflects the first mode recorded following ventilation start. It may not be the mode at the start time of ventilation. 


\section{Table 2. Association of PVA with baseline patient characteristics using PWP-GT model*}

\begin{tabular}{|c|c|c|c|c|c|c|}
\hline & \multicolumn{2}{|l|}{ Overall PVA } & \multicolumn{2}{|c|}{ Double triggering } & \multicolumn{2}{|c|}{ Flow mismatch } \\
\hline & $\begin{array}{l}\text { Estimate } \\
(95 \% \mathrm{Cl})\end{array}$ & $\begin{array}{l}\mathrm{P}- \\
\text { value }\end{array}$ & $\begin{array}{l}\text { Estimate } \\
(95 \% \mathrm{Cl})\end{array}$ & $\begin{array}{l}\mathrm{P}- \\
\text { value }\end{array}$ & $\begin{array}{l}\text { Estimate } \\
(95 \% \mathrm{Cl})\end{array}$ & $\begin{array}{l}\mathrm{P} \text { - } \\
\text { value }\end{array}$ \\
\hline Age (per 10 years) & $\begin{array}{l}1.02(0.94 \text { to } \\
1.12)\end{array}$ & 0.575 & $\begin{array}{l}1.06(0.94 \text { to } \\
1.19)\end{array}$ & 0.338 & $\begin{array}{l}1.07 \\
(0.95 \text { to } \\
1.21)\end{array}$ & 0.279 \\
\hline Sex & & 0.348 & & 0.691 & & 0.840 \\
\hline Female & Referent & & Referent & & Referent & \\
\hline Male & $\begin{array}{l}1.18(0.83 \text { to } \\
1.68)\end{array}$ & & $\begin{array}{l}1.10(0.69 \text { to } \\
1.74)\end{array}$ & & $\begin{array}{l}1.06 \\
(0.59 \text { to } \\
1.90)\end{array}$ & \\
\hline $\begin{array}{l}\text { Ideal body weight (per } 10 \\
\mathrm{~kg} \text { ) }\end{array}$ & $\begin{array}{l}1.06(0.92 \text { to } \\
1.23)\end{array}$ & 0.407 & $\begin{array}{l}1.00(0.82 \text { to } \\
1.22)\end{array}$ & 0.984 & $\begin{array}{l}1.30 \\
(1.05 \text { to } \\
1.61)\end{array}$ & 0.018 \\
\hline \multicolumn{7}{|l|}{ Chronic comorbidities } \\
\hline History of smoking & $\begin{array}{l}1.46(1.13 \text { to } \\
1.89)\end{array}$ & 0.004 & $\begin{array}{l}1.47 \text { (1.03 to } \\
2.09)\end{array}$ & 0.035 & $\begin{array}{l}1.44 \\
(0.94 \text { to } \\
2.20)\end{array}$ & 0.090 \\
\hline Heart disease & $\begin{array}{l}0.65(0.50 \text { to } \\
0.85)\end{array}$ & 0.002 & $\begin{array}{l}0.49(0.34 \text { to } \\
0.72)\end{array}$ & $<.001$ & $\begin{array}{l}0.84 \\
(0.53 \text { to } \\
1.32)\end{array}$ & 0.442 \\
\hline Lung disease & $\begin{array}{l}0.94(0.74 \text { to } \\
1.21)\end{array}$ & 0.634 & $\begin{array}{l}0.96(0.65 \text { to } \\
1.43)\end{array}$ & 0.841 & $\begin{array}{l}0.93 \\
(0.57 \text { to } \\
1.52)\end{array}$ & 0.764 \\
\hline Kidney disease & $\begin{array}{l}1.24(0.96 \text { to } \\
1.62)\end{array}$ & 0.105 & $\begin{array}{l}1.58(1.08 \text { to } \\
2.30)\end{array}$ & 0.017 & $\begin{array}{l}0.64 \\
(0.40 \text { to } \\
1.03)\end{array}$ & 0.064 \\
\hline Immunosuppression & $\begin{array}{l}0.76(0.52 \text { to } \\
1.11)\end{array}$ & 0.157 & $\begin{array}{l}0.57(0.36 \text { to } \\
0.91)\end{array}$ & 0.019 & $\begin{array}{l}0.98 \\
(0.59 \text { to } \\
1.62)\end{array}$ & 0.933 \\
\hline Neurologic & $\begin{array}{l}0.77(0.51 \text { to } \\
1.15)\end{array}$ & 0.194 & $\begin{array}{l}0.84(0.48 \text { to } \\
1.46)\end{array}$ & 0.536 & $\begin{array}{l}0.67 \\
(0.35 \text { to } \\
1.30)\end{array}$ & 0.235 \\
\hline Cirrhosis & $\begin{array}{l}1.57 \text { (1.06 to } \\
2.32)\end{array}$ & 0.024 & $\begin{array}{l}1.38(0.75 \text { to } \\
2.54)\end{array}$ & 0.297 & $\begin{array}{l}2.14 \\
(1.06 \text { to } \\
4.31)\end{array}$ & 0.034 \\
\hline Reason for ventilation & & 0.007 & & 0.026 & & 0.103 \\
\hline Post-surgical & Referent & & Referent & & Referent & \\
\hline
\end{tabular}




\begin{tabular}{|c|c|c|c|c|c|}
\hline Pneumonia/Sepsis/ARDS & $\begin{array}{l}1.48 \text { (1.01 to } \\
2.16)\end{array}$ & $\begin{array}{l}1.83 \text { (1.03 to } \\
3.26)\end{array}$ & & $\begin{array}{l}1.69 \\
(0.99 \text { to } \\
2.87)\end{array}$ & \\
\hline Neuro & $\begin{array}{l}0.67(0.37 \text { to } \\
1.20)\end{array}$ & $\begin{array}{l}0.74(0.33 \text { to } \\
1.68)\end{array}$ & & $\begin{array}{l}0.68 \\
(0.26 \text { to } \\
1.77)\end{array}$ & \\
\hline Other & $\begin{array}{l}1.52 \text { (1.02 to } \\
2.27)\end{array}$ & $\begin{array}{l}1.62 \text { (0.88 to } \\
3.00)\end{array}$ & & $\begin{array}{l}1.43 \\
(0.76 \text { to } \\
2.69)\end{array}$ & \\
\hline Ventilator mode & & & 0.003 & & 0.001 \\
\hline VC & Referent & Referent & & Referent & \\
\hline VC-SIMV & $\begin{array}{l}0.86 \\
1.55)\end{array}$ (0.48 to & $\begin{array}{l}0.83 \text { ( } 0.39 \text { to } \\
1.75)\end{array}$ & & $\begin{array}{l}1.13 \\
(0.43 \text { to } \\
2.99)\end{array}$ & \\
\hline PC & $\begin{array}{l}0.50 \text { (0.38 to } \\
0.68)\end{array}$ & $\begin{array}{l}0.45(0.29 \text { to } \\
0.69)\end{array}$ & & $\begin{array}{l}0.35 \\
(0.21 \text { to } \\
0.61)\end{array}$ & \\
\hline PC-SIMV & $\begin{array}{l}1.47(0.83 \text { to } \\
2.60)\end{array}$ & $\begin{array}{l}2.58 \text { (1.00 to } \\
6.69)\end{array}$ & & $\begin{array}{l}1.51 \\
(0.42 \text { to } \\
5.45)\end{array}$ & \\
\hline \multicolumn{6}{|c|}{$\begin{array}{l}\text { * PWP-GT model : Prentice, Williams, and Peterson gap time. Robust sandwich } \\
\text { variance estimates were used to account for the potential within patient } \\
\text { correlation. For each model, the terms were assessed for collinearity and } \\
\text { functional form. \#Overall PVA included flow starvation, double triggering, } \\
\text { ineffective effort, delayed triggering and cycle mismatch. }\end{array}$} \\
\hline
\end{tabular}




\title{
Table 3. Association of overall PVA with ventilator settings during different ventilator mode using PWP-GT model*
}

\author{
Estimate $(95 \% \mathrm{Cl}) \quad$ P-value
}

\section{VC ventilator mode}

VC-Vt per IBW setting (per $\mathrm{mL}$ )

$1.06(0.90$ to 1.23$)$

0.494

Respiratory rate setting

$1.02(0.99$ to 1.05$)$

0.221

$\operatorname{PEEP}\left(\mathrm{cm} \mathrm{H}_{2} \mathrm{O}\right)$

1.02 (0.97 to 1.07$)$

0.398

\section{VC-SIMV ventilator mode}

Peak inspiratory flow setting

$1.12(1.04$ to 1.20$)$

0.002

Respiratory rate setting

0.93 (0.79 to 1.10$)$

0.409

PEEP $\left(\mathrm{cm} \mathrm{H}_{2} \mathrm{O}\right)$

$0.82(0.70$ to 0.95$)$

0.009

\section{PC ventilator mode}

Inspiratory time set (per 0.1 second up to 1.2 seconds)

0.92 (0.82 to 1.02$)$

0.100

Inspiratory time set (per 0.1 seconds after 1.2 seconds)

1.07 (0.98 to 1.17 )

0.158

Pressure setting (per 1 unit up to 12)

0.95 ( 0.87 to 1.04$)$

0.286

Pressure setting (per 1 unit after 12)

1.10 (1.03 to 1.17$)$

0.006

PEEP (per $\mathrm{cm} \mathrm{H}_{2} \mathrm{O}$ )

0.98 (0.91 to 1.05$)$

0.592

* PWP-GT model: Prentice, Williams, and Peterson gap time. As there were different settings in different modes, we did 3 analyses limited to 3 ventilation modes due to rare frequency of PC-SIMV ventilation, including among the 3 analysis a total 666 patients underwent 686 episodes of mechanical ventilation.

Models were fit using data from patients with the given ventilator delivery type (mode) at any point during their episode of mechanical ventilation, with only the time under that delivery mode contributing to the given analysis. All models were adjusted for age, sex, and ideal body weight, history of smoking, heart disease, chronic lung disease, kidney disease, immunosuppression, neurologic disease, cirrhosis, and reason for initiation of mechanical ventilation. In addition to the baseline covariables listed, each model included the mode-specific settings as time-dependent covariables.

Robust sandwich variance estimates were used to account for the potential within patient correlation. For each model, the terms were assessed for collinearity and functional form. When evidence of nonlinearity was found, the piecewise linear spline was chosen for ease of interpretation.

Other notes: Each model was stratified by number of prior asynchrony events. Multiple events were allowed and start/stop times were re-started after a change in ventilator mode or an asynchrony event. 


\section{Table 4. Post-extubation or -weaning success outcomes $(n=599) *$}

$\begin{array}{lll}\text { Outcome } & \text { Patients without any kind } & \text { Patients with at least one } \\ \text { of } \mathrm{PVA}^{\#} & \mathrm{PVA}^{\#} \text { event } \\ (\mathrm{N}=471) & (\mathrm{N}=128)\end{array}$

28-day hospital-free days, median (Q1, Q3)

$19.7(11.8,23.5)$

$15.2(0.1,21.2)$

Hospital mortality, n (\%)

$35(7 \%)$

$18(14 \%)$

* Patients who died on ventilator $(n=97)$ were excluded from the analysis. We describe hospital-free days through 28 days - defined as the number of days alive and out of hospital during 28 days after extubation or weaning success. Weaning success was defined as patients who received tracheostomy and no longer required mechanical ventilation.

\#PVA: patient ventilator asynchrony.

Table 5. Association between PVA and post-extubation or -weaning success outcomes $(n=599)$ *

\begin{tabular}{|c|c|c|c|c|c|c|}
\hline & \multicolumn{2}{|l|}{ Overall PVA } & \multicolumn{2}{|c|}{ Double triggering } & \multicolumn{2}{|l|}{ Flow starvation } \\
\hline & $\begin{array}{l}\text { Estimate }(95 \% \\
\mathrm{Cl})\end{array}$ & $\begin{array}{l}\text { P- } \\
\text { value }\end{array}$ & stimate $(95 \%$ & $\begin{array}{l}\text { P- } \\
\text { value }\end{array}$ & $\begin{array}{l}\text { Estimate }(95 \% \\
\text { Cl) }\end{array}$ & $\begin{array}{l}\text { P- } \\
\text { value }\end{array}$ \\
\hline $\begin{array}{l}\text { Hospital-free } \\
\text { days }(28)\end{array}$ & $\begin{array}{l}-4.00(-5.81 \text { to } \\
-2.18)\end{array}$ & & ) & 8 & $\begin{array}{l}-4.24(-7.01 \text { to } \\
-1.47)\end{array}$ & .003 \\
\hline $\begin{array}{l}\text { Hosp } \\
\text { morta }\end{array}$ & $\begin{array}{l}1.87(0.98 \text { to } \\
3.58)\end{array}$ & 0.057 & $(0.39$ to & 0.989 & $\begin{array}{l}1.37(0.54 \text { to } \\
3.48)\end{array}$ & 0.511 \\
\hline \multicolumn{7}{|c|}{$\begin{array}{l}\text { * Models are linear regression for hospital-free days and logistic regression for hospital mortality. } \\
\text { Models account for correlation between multiple observations per subject with robust variance } \\
\text { estimates using the generalized estimating equations approach). All models are adjusted for history } \\
\text { of smoking, heart disease, reason for intubation, and initial ventilation delivery mode. Patients who } \\
\text { died on ventilator ( } n=97) \text { were excluded from the analysis. }\end{array}$} \\
\hline \multicolumn{7}{|c|}{$\begin{array}{l}\text { \#Overall PVA included flow starvation, double triggering, ineffective effort, delayed triggering and cycle } \\
\text { mismatch. }\end{array}$} \\
\hline \multicolumn{7}{|c|}{$\begin{array}{l}\text { t Estimates are odds ratios and represent the increased odds of hospital mortality associated with } \\
\text { the given asynchrony type. }\end{array}$} \\
\hline
\end{tabular}

\section{Figures}




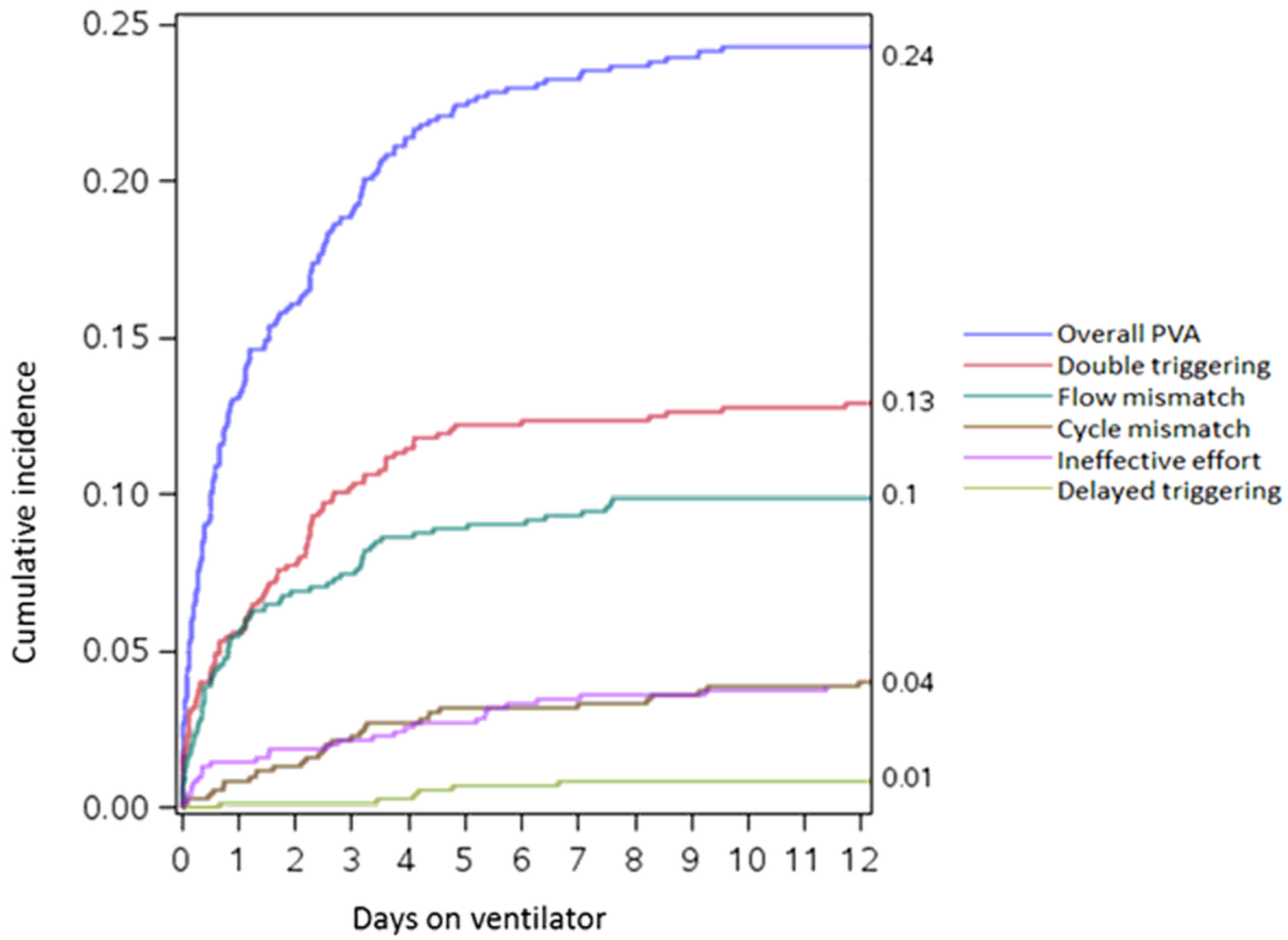

Figure 1

Cumulative incidence of asynchrony over the first 12 days of mechanical ventilation. 


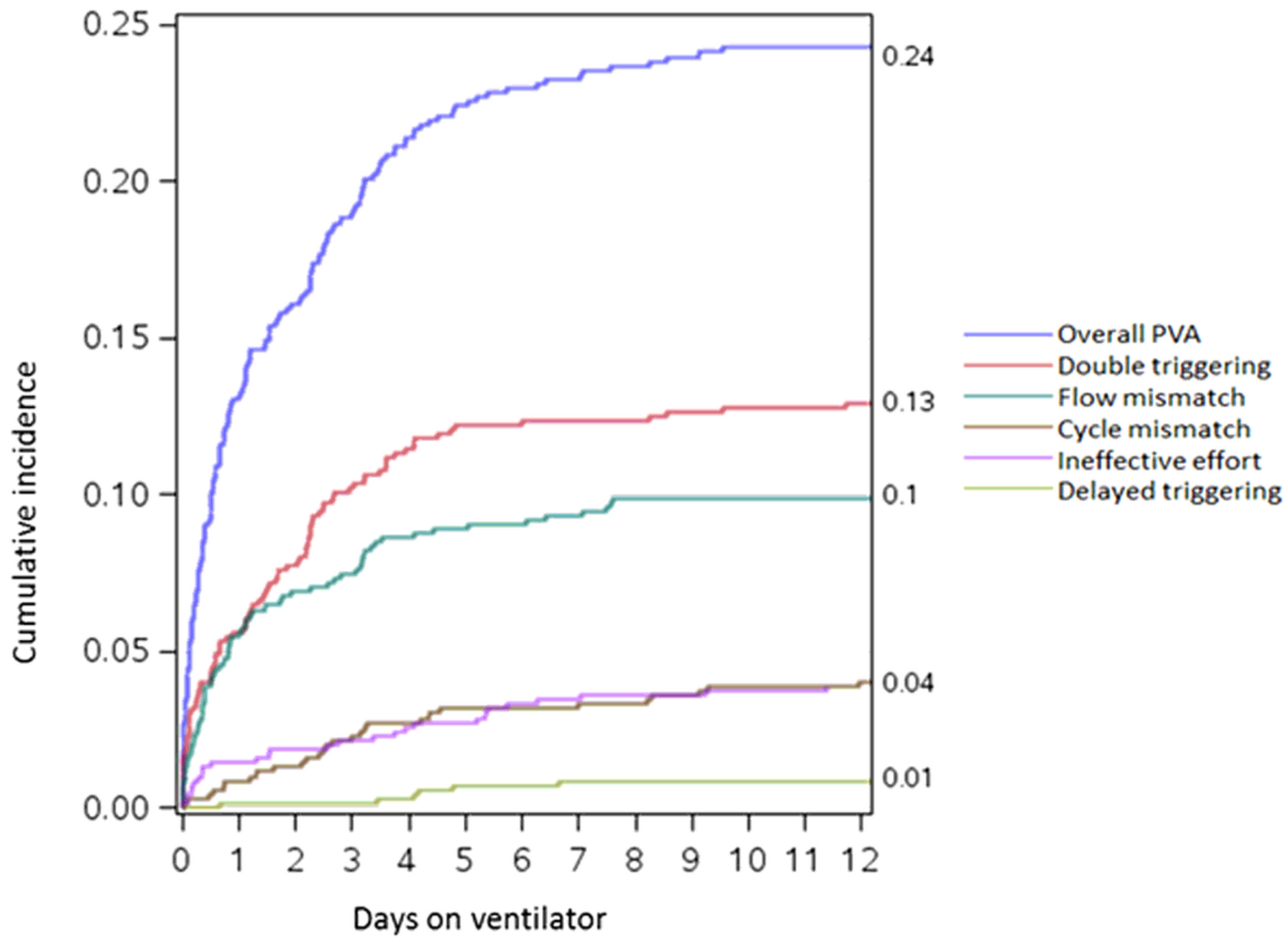

Figure 1

Cumulative incidence of asynchrony over the first 12 days of mechanical ventilation. 


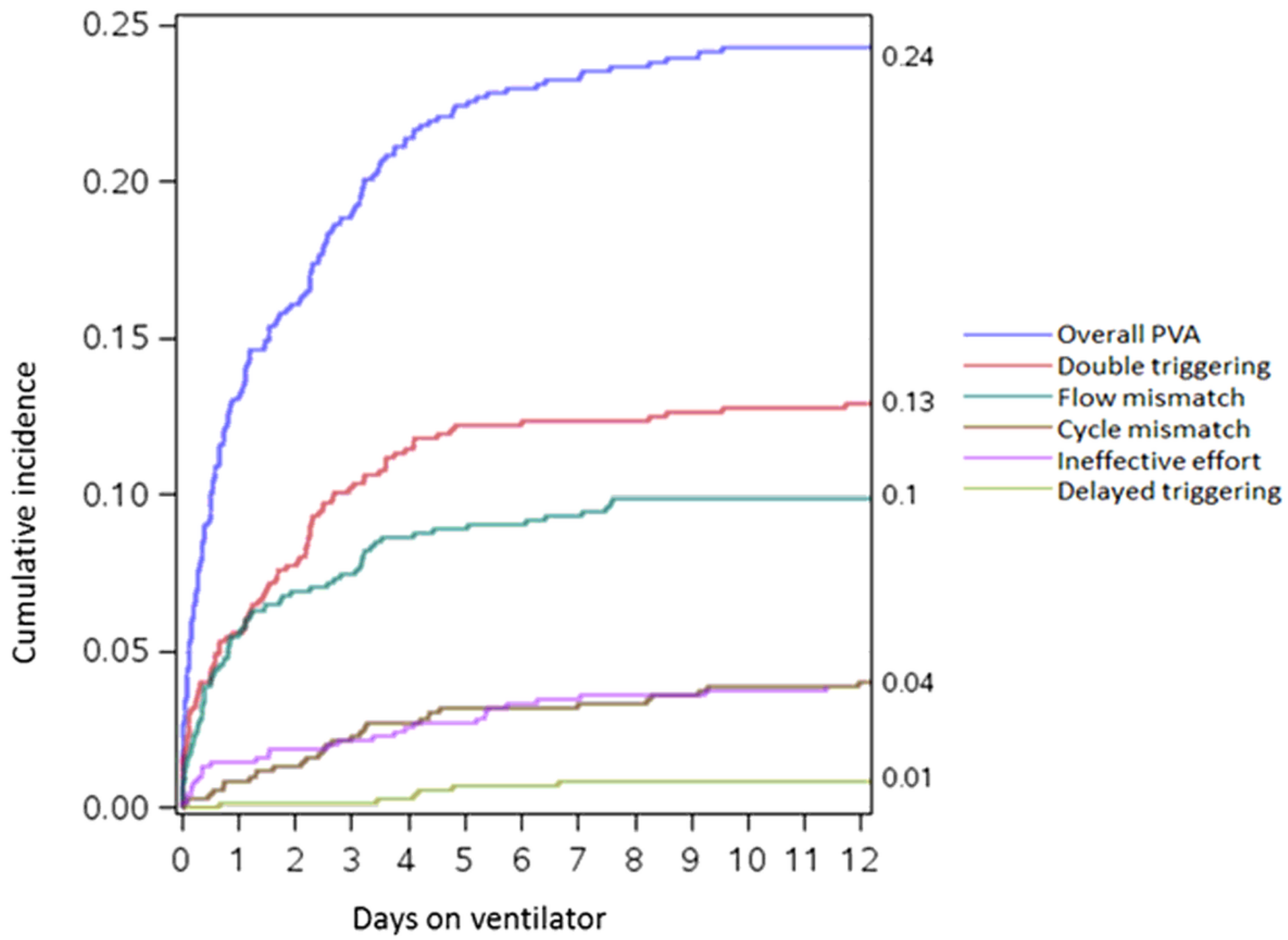

Figure 1

Cumulative incidence of asynchrony over the first 12 days of mechanical ventilation. 


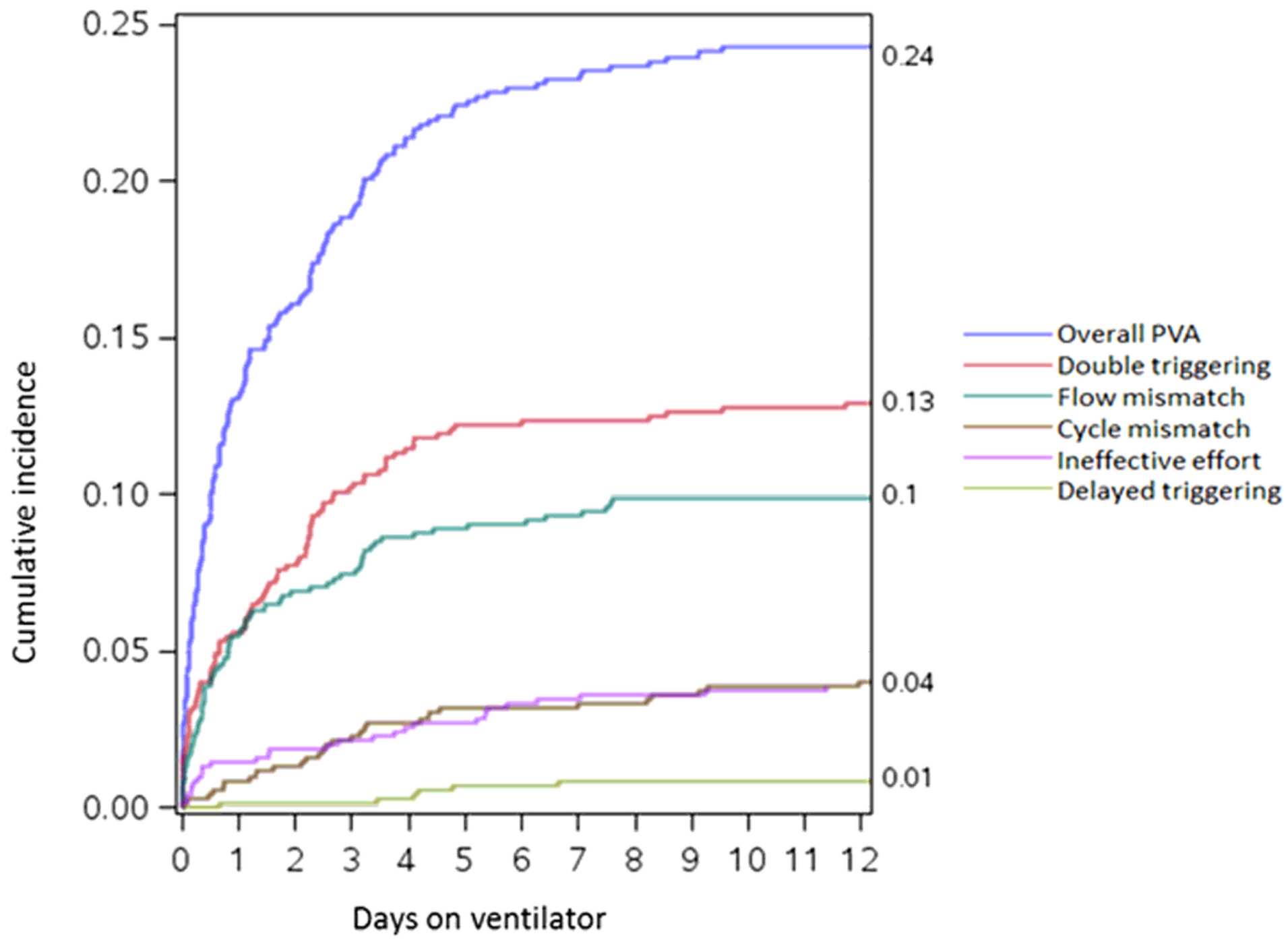

Figure 1

Cumulative incidence of asynchrony over the first 12 days of mechanical ventilation. 


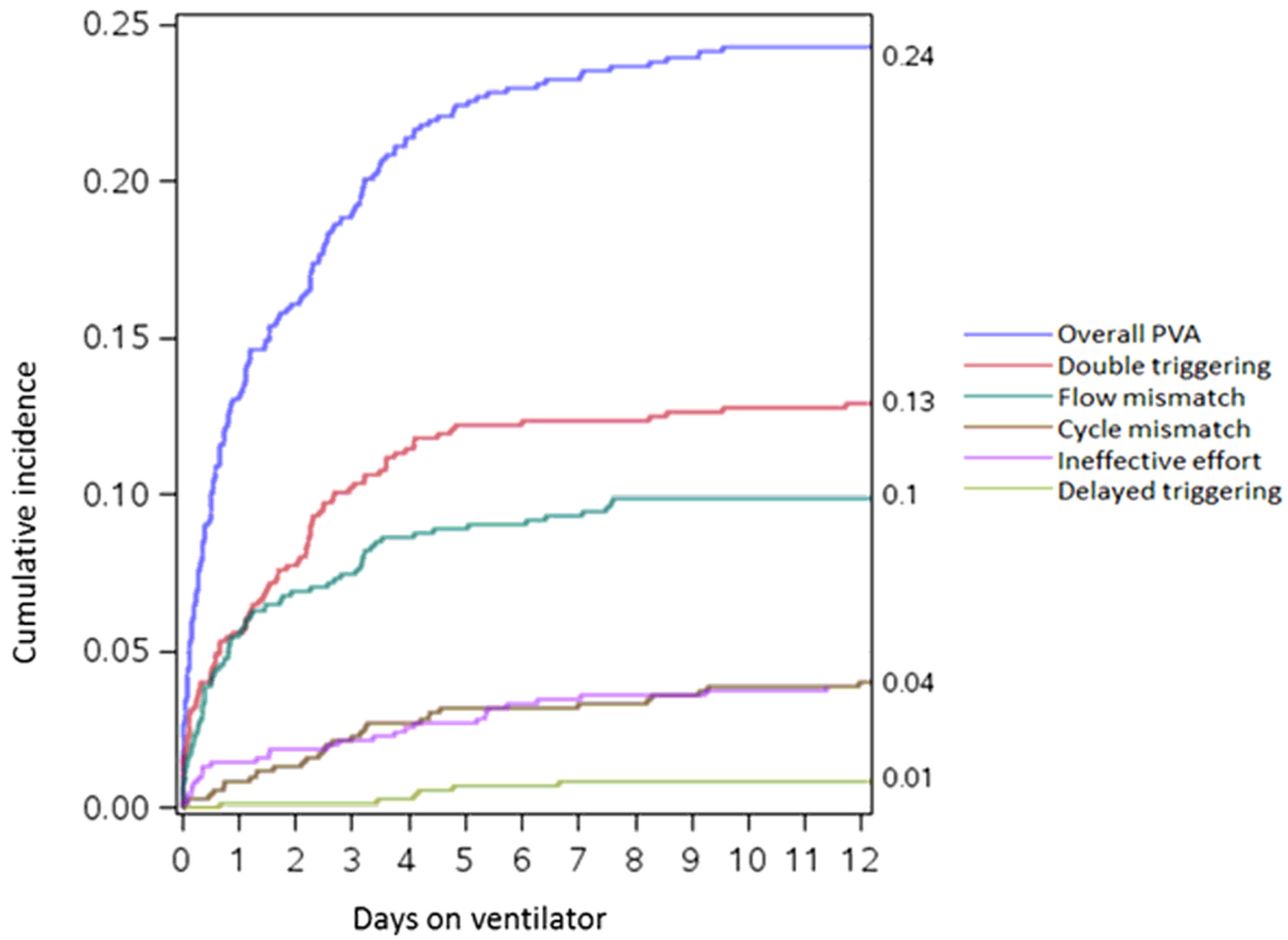

Figure 1

Cumulative incidence of asynchrony over the first 12 days of mechanical ventilation. 


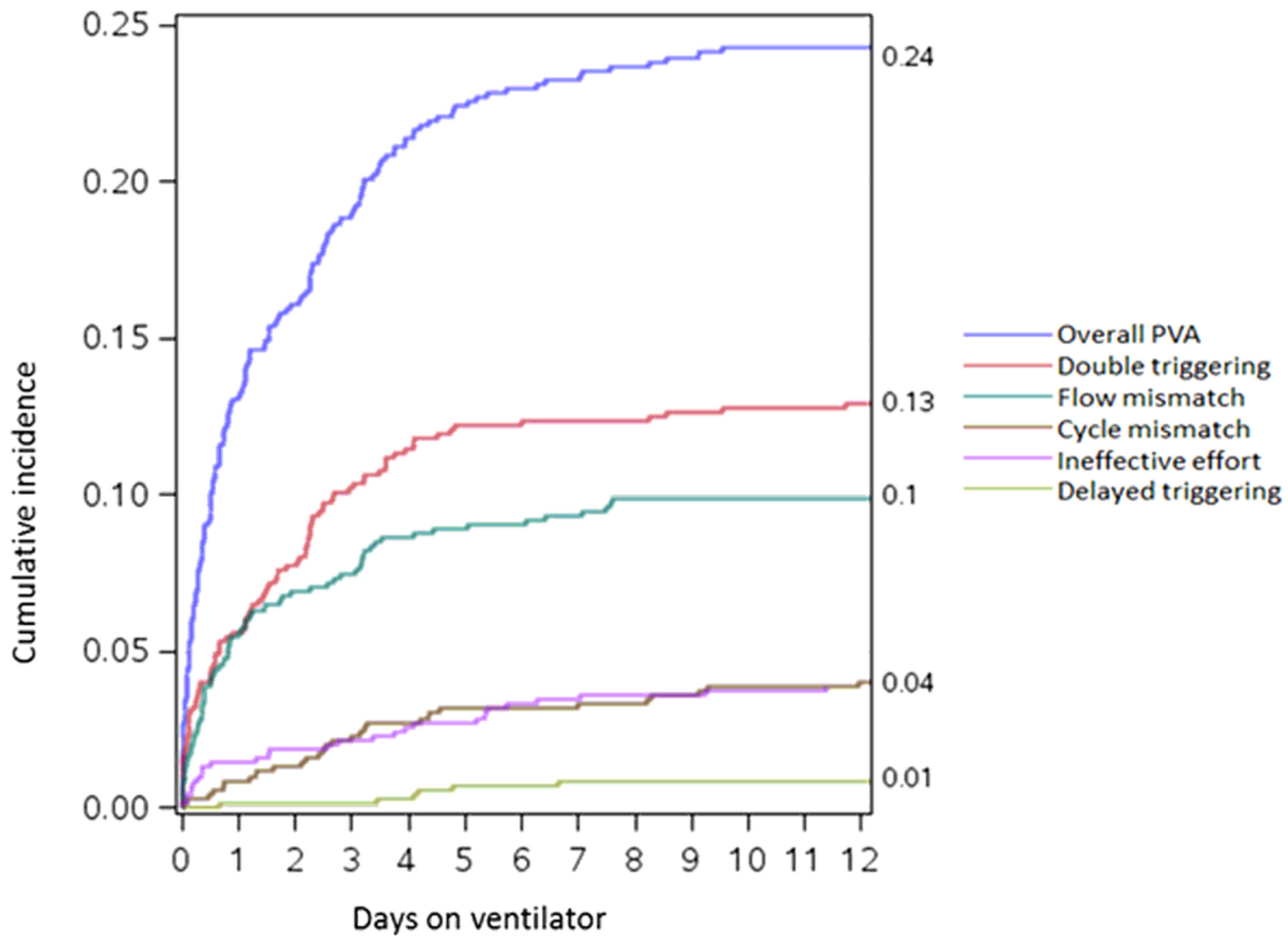

Figure 1

Cumulative incidence of asynchrony over the first 12 days of mechanical ventilation. 


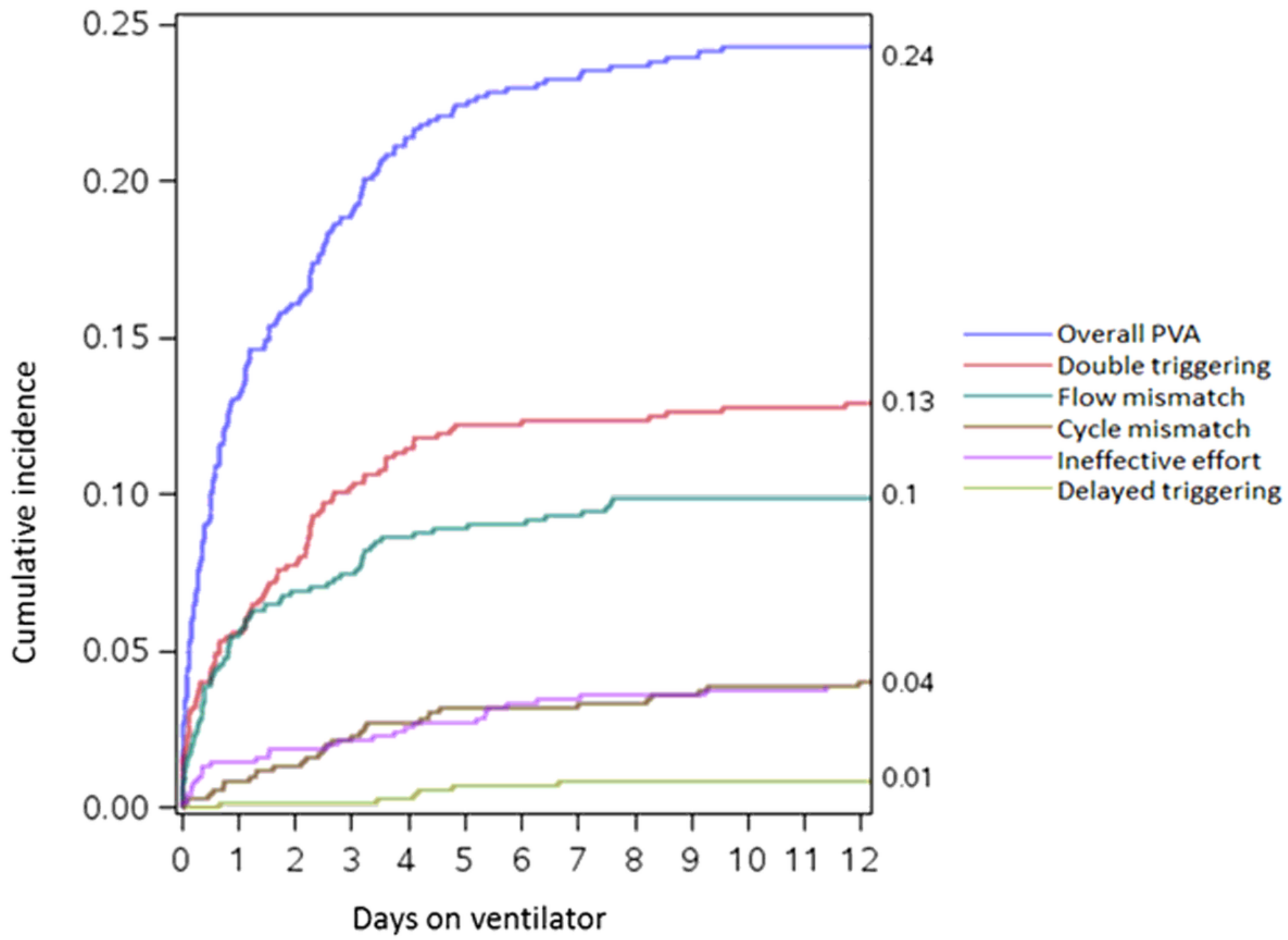

Figure 1

Cumulative incidence of asynchrony over the first 12 days of mechanical ventilation. 


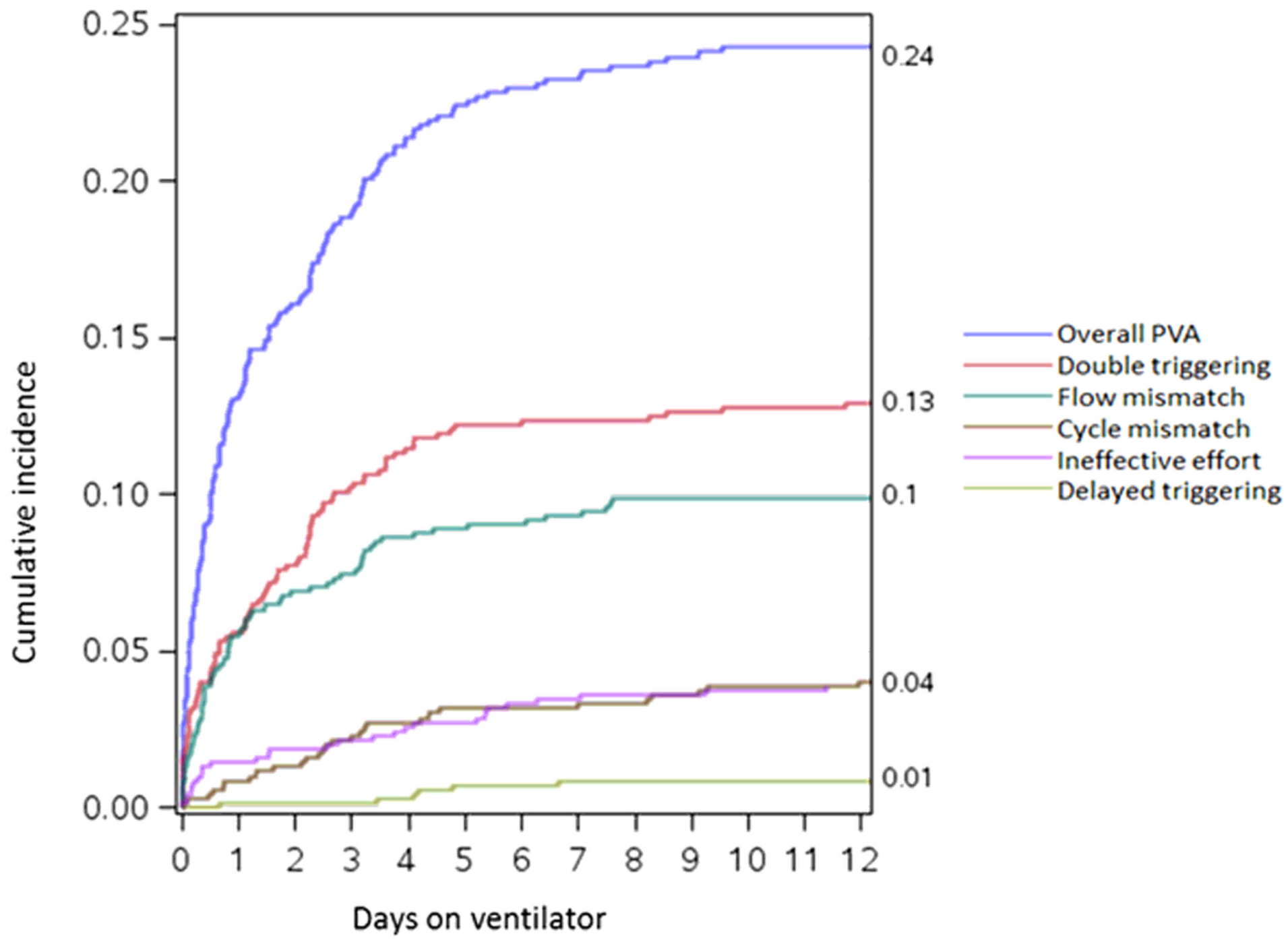

Figure 1

Cumulative incidence of asynchrony over the first 12 days of mechanical ventilation. 


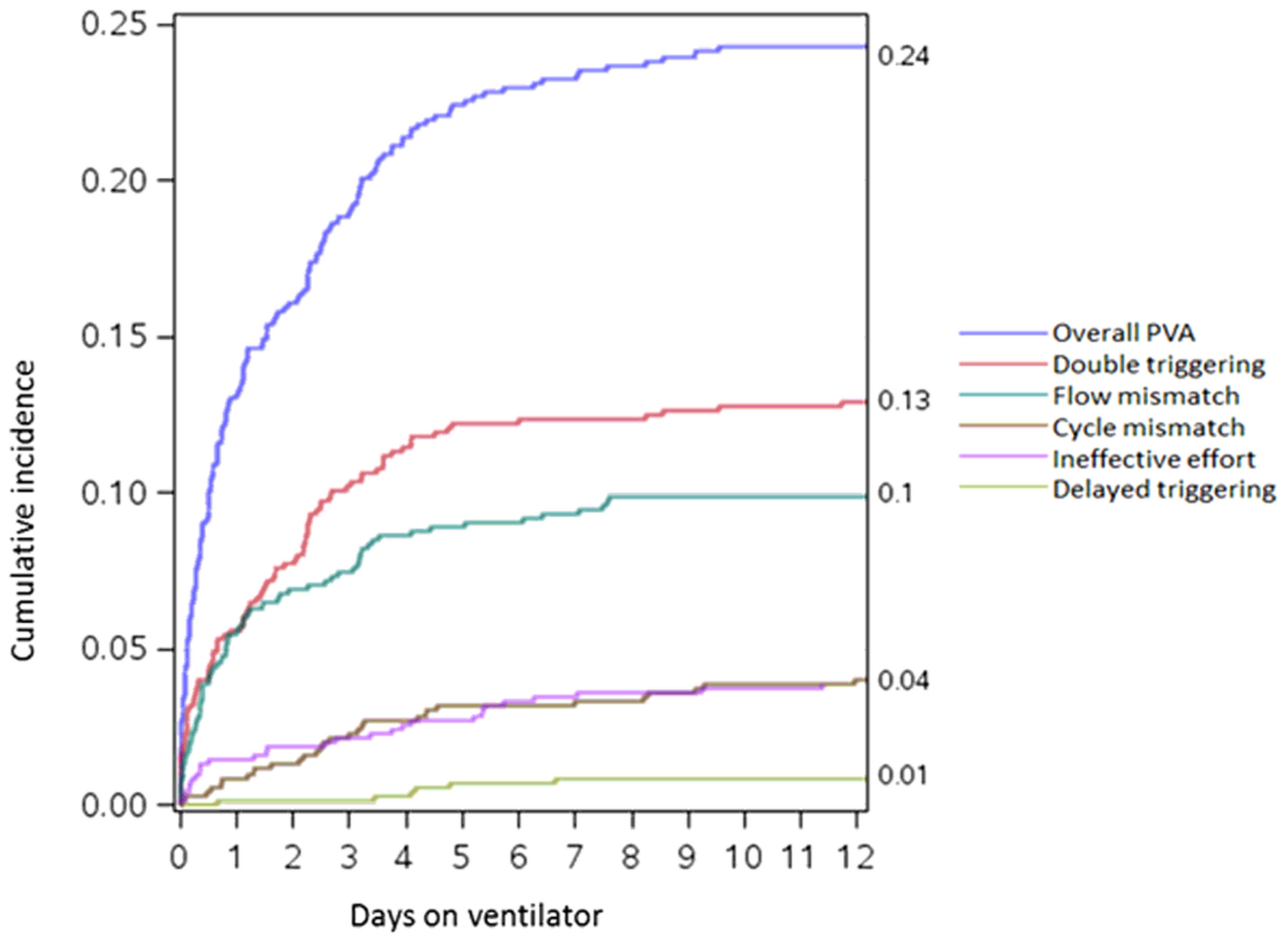

Figure 1

Cumulative incidence of asynchrony over the first 12 days of mechanical ventilation.

\section{Supplementary Files}

This is a list of supplementary files associated with this preprint. Click to download.

- Additionalfile1.pdf

- Additionalfile1.pdf 